UCRL-53694

Distribution Category UC-34a

DISCLAIMER

DCRL- -53694

This report was prepared as an scoount of work sponsored by an aseacy of the United Sutes DE86 009348 Government. Neither the United States Government dor any asenc, thereof, sor any of their employees, makes any warranty, express or implied, or asumes eny iegal linbility or responsibility for the sceuracy, completereas, or usefulbess of any information, apparates, product, or process disclowed, of represenis that its use would not infringe privitely owned rights. Reference herein to any specisk commercial product, process, or service by trede name, trademark, manufacturer, of otherwice does not secesurily coestitute or inply its eadorsemest, recoenand opinions of aring by the United States Gowerameat or any seacy thereof. The viene and opinions of avthors expreased berein do not necesarily state or neflect thoee of the United States Government or any agency thereor.

\title{
Calculation of Hugoniot Values from Atomic Properties
}

\author{
Franklin E. Walker \\ F. Gary Walker \\ J. Bruce Walker
}

Manuscript date: January 1986

\section{LAWRENCE LIVERMORE NATIONAL LABORATORY University of California - Livermore, California - 94550}

Available from: National Technical Information Service - US. Department of Commerce 5285 Port Royal Road • Springfield, VA 22161 • A02 • (Microfiche A01) 


\section{Contents}

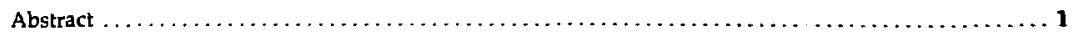

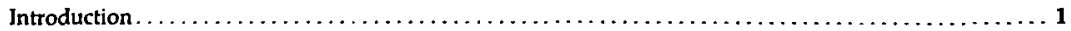

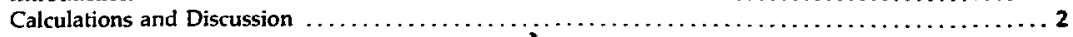

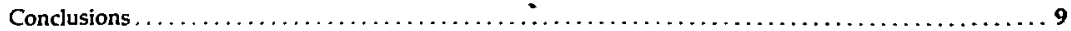

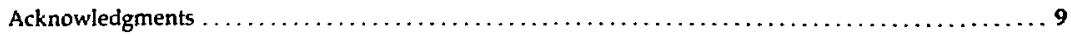

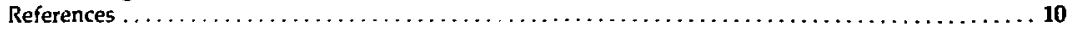




\title{
Calculation of Hugoniot \\ Values from Atomic \\ Properties
}

\begin{abstract}
A relatively simple equation is presented for use in calculating the Hugoniot values of any condensed element from its atomic weight, atomic radius, and dersity. Calculations from the equation are compared with data for many elements, and a discussion of the development and utility of the equation is included. The equation also appears to be useful for the gaseous elements when they are in condensed phases.
\end{abstract}

\section{Introduction}

Considerable equipment and instrumentation are required to measure accurately the velocity of a shock produced in a condensed material by a high-velocity impacting plate, and it would be very useful to have a simple calculational method to obtain reasonably accurate Hugoniot values. The basic description of this shock phenomenon for a material initially at rest is given by the relationship

$\left(P-P_{v}\right)=\rho U_{s} U_{p}$,

in which, with three variables (pressure $P$, shock velocity $U_{s}$, and particle velocity $\left.U_{p}\right)$, two are measured to allow calculation of the third., ${ }^{1,2}$ The injtial density is $\rho$.

In molecular dynamics studies ${ }^{3-6}$ of the effects of shock waves in condensed substances, a Hugoniot "experiment" was conducted on the computer. ${ }^{4}$ A flying plate was propelled mathematically with increasing velocity increments into an acceptor material; the velocity of the induced shock wave was then calculated. Comparison of these results in simulated organic substances with data for organic plastics and explosives (see Fig. 1) showed a very good correlation, which was corroborated in an independent study. ${ }^{7}$ Extrapolation of the calculated values to $P=0$ gave a good approximation of representative sonic velocities $\mathrm{c}$.

Subsequently, calculations of $u_{s}=f(P)$ in materials with properties representative of aluminum, iron, and tungsten were completed ${ }^{8}$ and with a reasonable normalization they matched well the Hugoniot data for these materials over a range of $P$ of about $40-460 \mathrm{GPa}$, as shown in Table 1 and Fig. 2.

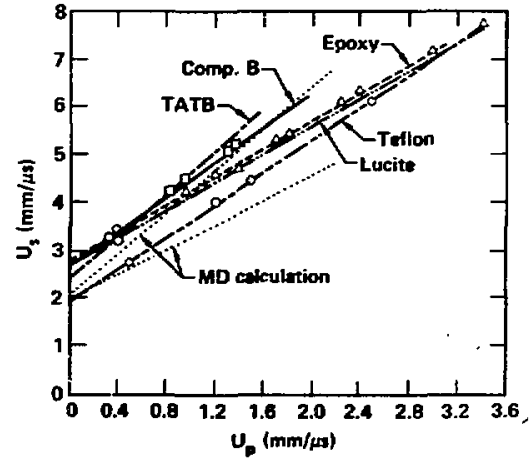

Figure 1. Comparison of computer-calculated Hugnniot curves with experimental data for organic plastics and high explosives.

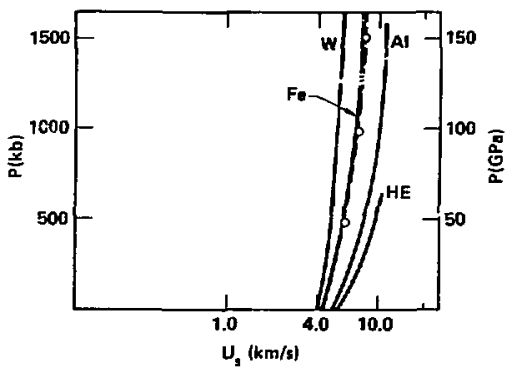

Figure 2. Computer-calculated Hugonicts for tungsten, lead, and aluminum. 
Table 1. Computer calculated Hugoniut results for Fe.

\begin{tabular}{|c|c|c|c|c|c|}
\hline \multicolumn{2}{|c|}{ Experimental } & \multicolumn{2}{|c|}{ Calculated } & \multirow[b]{2}{*}{ Max error } & \multirow[b]{2}{*}{ Min. errot } \\
\hline$U_{,}(\mathrm{km} / \mathrm{s})$ & $U_{s}(\mathrm{~cm} / \mathrm{s})^{2}$ & $\overline{P(G P a)}$ & $U_{,}$ & & \\
\hline $\mathbf{1}$ & 5.404 & 42.5 & 5.826 & $=0.65$ & \pm 0.32 \\
\hline 3 & 8.74 & 206.0 & $8.74^{b}$ & \pm 1.46 & \pm 0.73 \\
\hline $\mathbf{5}$ & 11.812 & 464.0 & 10.502 & \pm 212 & \pm 1.05 \\
\hline \multicolumn{6}{|c|}{$\begin{array}{l}U_{s}=3.635+1.802 U_{v}-0.0333 U_{p}^{2} \\
\text { Adjusted. } \\
\text { The maximum and minimum errors are based on the possible errors in the } \\
\text { alculation time where the maximum error is } \geq 1 \times 10^{-14} \text { and the minimum }\end{array}$} \\
\hline
\end{tabular}

\section{Calculations and Discussion}

\section{Derivation of the Equations}

The foregoing results suggested that satisfactory Hugoniot values should be calculable from a few basic atomic properties, and a simple equation based on these properties and an exponential $f(P)$ was found that provided a good approximation of these values for the ten diverse elements in Table 2 . At $P>40 \mathrm{GPa}$, particularly, the values were given precisely over large ranges of $P$. Again, at $P=0$ the sonic velocities were approximated.

This equation,

$U_{\mathrm{s}}=f(P)\left(r_{A} / \omega_{A}\right)^{1 / 4} \rho^{-0.1}$

where

$f(P)=\left(0.42 P+10.3 P^{1 / 2}+12\right)$,

works well for the elements we reviewed in Groups IB, IIB, IVB, VB, VIB, IIA, and VIII. Here $r_{A}$ is atomic radius and $\omega_{A}$ is atomic weight as tuinen from a periodic table. ${ }^{9}$ The results indicate that $\mathrm{Er}_{1}$. (2) inay also provide satisfactory values ior VIIB $t,-m e n t s$ and first-order values or better for any condensed element. Representative calculated and experitzental results are compared in Table 2, and values for beryllium, nickel, and gold are plctted in Fig. 3 .

The $f(P)$ carve of Eq. (3) is given in Fig. 4. It is empirically dirived from an experimental data set, ${ }^{10}$ but it :ould be calculated from a selected Morse (or similar) potential equation. The point of this discussion is that the primary properties that determine the shock values for all elements in this study are simply the atomic weight, the atomic radius, and the initiaî density. One simple $f(P)$ equation serves well for the 22 elements of Tables 2 and 3.

A small change in the lower segment of the $f(P)$ curve, also shown in Fig. 4, improves the fit

Table 2. $U_{s}$ values in $\mathrm{mm} / \mu$ s calculated for ten elements rvith Eq. (2) and compared with experimental data.

\begin{tabular}{llllcccc}
\hline \multirow{2}{*}{ Element } & \multicolumn{2}{c}{$20 \mathrm{GPa}$} & \multicolumn{2}{c}{$60 \mathrm{GPa}$} & \multicolumn{2}{c}{$160 \mathrm{GPa}$} \\
\cline { 2 - 7 } & Data & Calc. & Data & Calc. & Dala & Calc. \\
\hline Beryllium & 9.50 & 9.32 & 11.2 & 11.3 & 15.0 & 14.4 \\
Titanium & 5.57 & 6.01 & 6.80 & 7.29 & 9.15 & 9.26 \\
Iron & 5.00 & 5.27 & 5.90 & 6.38 & 8.00 & 8.11 \\
Nickel & 5.27 & 5.12 & 6.20 & 6.20 & 8.05 & 7.89 \\
Silver & 4.15 & 4.49 & 5.10 & 5.44 & 6.70 & 6.91 \\
Tantalum & 3.86 & 3.80 & 4.46 & 4.60 & 5.54 & 5.85 \\
Tungsten & 4.31 & 3.68 & 4.76 & 4.46 & 5.90 & 5.66 \\
Platinum & 3.88 & 3.57 & 4.60 & 4.33 & 5.73 & 5.50 \\
Gild & 3.58 & 3.65 & 4.20 & 4.42 & 5.40 & 5.61 \\
Uranium & 3.00 & 3.43 & 3.80 & 4.16 & - & 5.28 \\
\hline
\end{tabular}




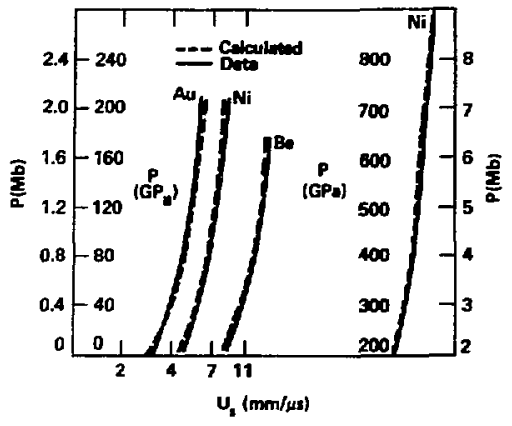

Figure 3. $U_{\mathrm{s}}$ vs $P$ curves for beryllium, nickel, and gold calculated with Eq. (2).

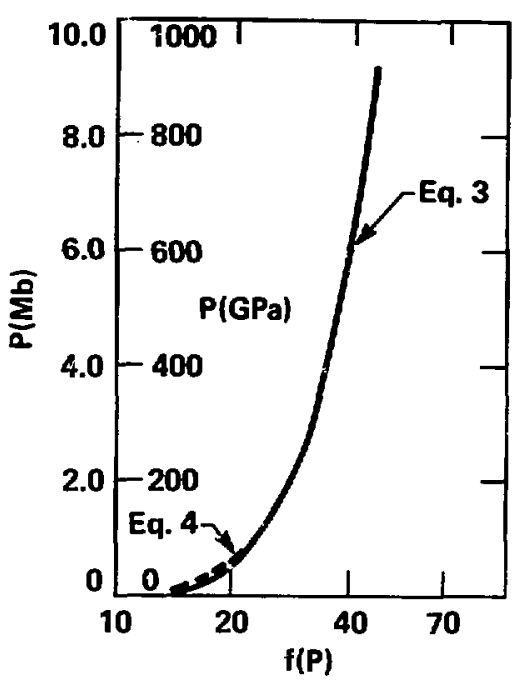

Figure 4. The $f(P)$ curve of Eq. (3) with the small change noted at the low end from Eq. (4).

Table 3. Comparison of the sonic velocities extrapolated from the data in Ref. 11 and those calculated for the elements in this study by setting $P=0$ in Eq. (2) and making the correction for relative electron density where appropriate.

\begin{tabular}{|c|c|c|c|c|}
\hline \multirow{3}{*}{$\frac{\text { Element }}{\text { Eithium }}$} & \multicolumn{4}{|c|}{ 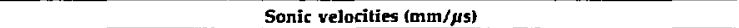 } \\
\hline & \multirow{2}{*}{$\begin{array}{l}\text { Data } \\
\text { extrapolation }\end{array}$} & \multirow[t]{2}{*}{ Measured } & \multicolumn{2}{|c|}{$\begin{array}{c}\text { Calculated } \\
(P=0)\end{array}$} \\
\hline & & & 7.12 & $4.40^{\circ}$ \\
\hline Beryllium & 8.00 & 12.9 & 6.70 & \\
\hline Carbon & - & - & 5.81 & \\
\hline Nitrogen ${ }^{2}$ & - & 1.50 & 5.02 & \\
\hline Oxygen" & - & 2.00 & 4.67 & \\
\hline Sodium" & 2.63 & & 5.22 & $3.23^{b}$ \\
\hline Magnesiuni & 4.49 & 5.77 & 5.75 & \\
\hline Aluminum & 5.94 & 6.42 & 5.21 & \\
\hline Potassium ${ }^{2}$ & 1.97 & - & 4.88 & $3.02^{b}$ \\
\hline Titanium & 5.22 (4.88) & - & 4.32 & \\
\hline Iron & 3.57 & 5.85 & 3.78 & \\
\hline Nickel & 4.60 & - & 3.68 & \\
\hline Copper & 3.94 & 4.88 & 3.63 & \\
\hline Zinc & 3.01 & - & 3.76 & \\
\hline Silver & 3.23 & 3.65 & 3.22 & \\
\hline Tantalum & 3.41 & - & 2.73 & \\
\hline Tungsten & 4.03 & 5.22 & 2.64 & \\
\hline Platinum & 3.60 & 3.26 & 2.57 & \\
\hline Gold & 3.06 & 324 & 2.62 & \\
\hline Lead'2 & 2.05 & - & 2.31 & $1.43^{b}$ \\
\hline Bismuth & 1.83 & - & 2.32 & $1.44^{b}$ \\
\hline Uranium & 2.49 & 2.47 & 2.47 & \\
\hline
\end{tabular}

${ }^{2}$ Corrected by the factor for low relative electron density.

Using the $f(P)$ from Eq. (6). 
for some of the elements in Grou:s IIA, IIIA, IB, and IIB. The equation for this segment is

$f(P)=\left(12.4 P-0.37 P^{1 / 2}+12\right)$.

A comparison of shock values for magnesium, aluminum, copper, and zinc calculated with $f(P)$ of Eq. (4) is made in Table 4 , and the values for magnesium, aluminur 1 , and copper are plotted in Fig. 5.

$U_{s}$ is a relatively weak function of $P$, as had been observed earlier. ${ }^{11}$ The general shape of the $f(P)$ curve from Eq. (3) (see Fig. 4) compares favorably with that seen at the sonic, thermal, and shock "barriers," as shown in Fig. 6." Also, from the Hugoniot data for one element near the center of the periodic table, such as iron or nickel, an $f(P)$ curve can be derived to use with all the element groups reviewed herein.

\section{Correction for Large Atomic Volume}

The only elements in the list of 22 discussed here for which the calculated values vary (high) more than about $8 \%$ at lower pressures ( $<40 \mathrm{GPa})$ are the ones with very large atomic volumes. More precisely, these are the elements with very small average electron densities (atomic number/atomic volume) relative to their neighbors in the center of their atomic table rows. Specifically, these are the Group IA elements listed (lithium, potassium, sodium), lead and bismuth, and the liquefied gases, $\mathrm{N}_{2}$ and $\mathrm{O}_{2}$. Zinc was a little low in relative electron density, and it had calculated values of $U_{s}$ that were a little high.

It is simple to correct for this factor. because for all of these elements the calculated $U_{\mathrm{s}}$ values are a factor of about 1.15 high at $10 \mathrm{GPa}$ and nearly correct at $70 \mathrm{GPa}$. A linear empirical correction based on Eq. (5) brings the values for these

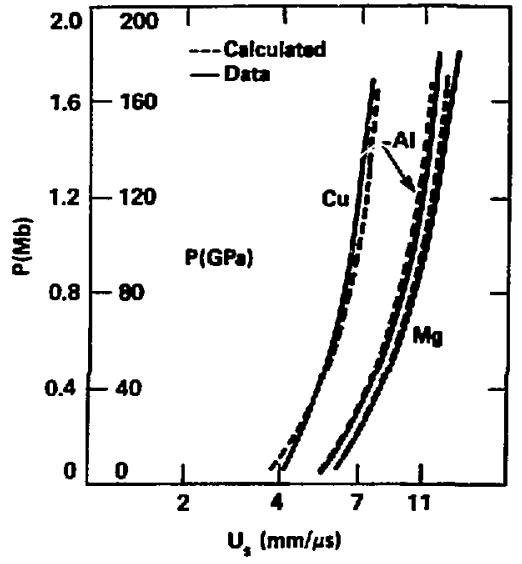

Figure 5. Comparison of shock velocities calculated with $\mathrm{Eq}$. (2) and the $f(P)$ of $\mathrm{Eq}$. (4) with data for magnesium, aluminum, and copper.

elements into closer agreement with the data at $<60 \mathrm{GPa}$ :

$k=0.4 P+0.8$.

Here $k$ is the $U_{s}$ correction factor, and $P$ is the pressure in $\mathrm{Mb}$. Table 5 compares the Group $1 \mathrm{~A}$ and the lead and bismuth values before and after correction. Comparison curves for lithium and potassium are given in Fig. 7 and for lead and bismuth in Fig. 8. These are some of the elements for which one would expect the shock velocity to be most difficult to calculate by this method, yet the results are reasonable.

Table 4. Comparison of Hugoniot values calculated with Eq. (2) with $f(P)$ of Eq. (4), for $P=10$ to 160 GPa.

\begin{tabular}{|c|c|c|c|c|c|c|c|c|c|c|c|c|}
\hline \multirow[b]{3}{*}{ Element } & \multicolumn{12}{|c|}{$P$ (GPa) } \\
\hline & \multicolumn{2}{|c|}{10} & \multicolumn{2}{|c|}{20} & \multicolumn{2}{|c|}{40} & \multicolumn{2}{|c|}{60} & \multicolumn{2}{|c|}{100} & \multicolumn{2}{|c|}{160} \\
\hline & Data ${ }^{2}$ & Calc. & Data & Calc. & Data & Calc. & Data & Calc. & Data & Calc. & Data & Calc \\
\hline Magnesium & 6.37 & 6.29 & 6.97 & 6.86 & 8.17 & 8.02 & 9.25 & 9.17 & 11.1 & 10.9 & 13.3 & 123 \\
\hline Aluminum & 5.80 & 5.70 & 6.50 & 6.22 & 7.26 & 7.27 & 9.53 & 8.32 & 10.0 & 9.88 & 11.7 & 11.2 \\
\hline Copper & 4.27 & 3.97 & 4.55 & 4.33 & 5.17 & 5.06 & 5.70 & 5.79 & 6.52 & 6.88 & 750 & 7.78 \\
\hline Zinc & 3.74 & 4.11 & 4.10 & 4.49 & 4.82 & 5.24 & 5.55 & 5.99 & 6.50 & 7.12 & 7.72 & 8.05 \\
\hline
\end{tabular}

all $U_{s}$ values are given as mm/ $\mu \mathrm{s}$. 
Velocity (mm/ $\mathrm{ms}$ )
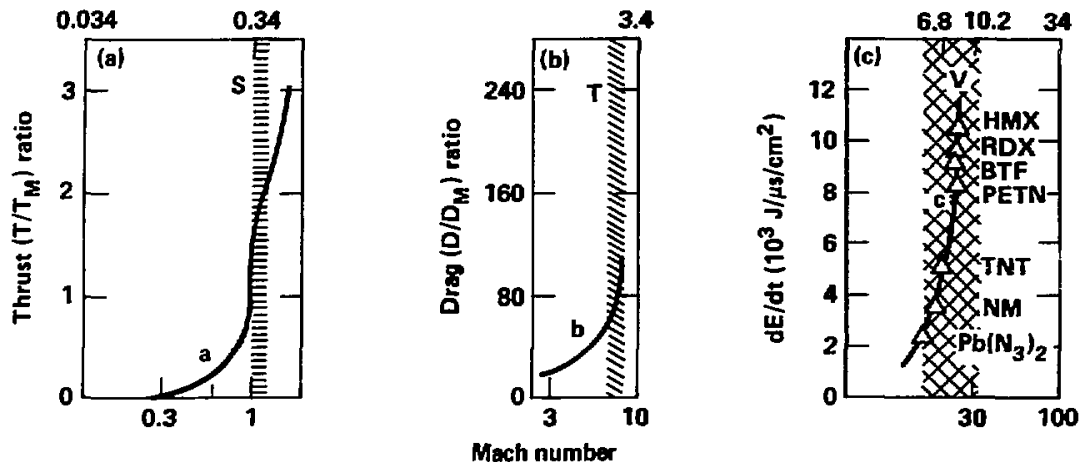

Figure 6. Representation of the sonic, thermal, and shock "barriers" as related to sonic flow, hypersonic flow, and detonation velocities.

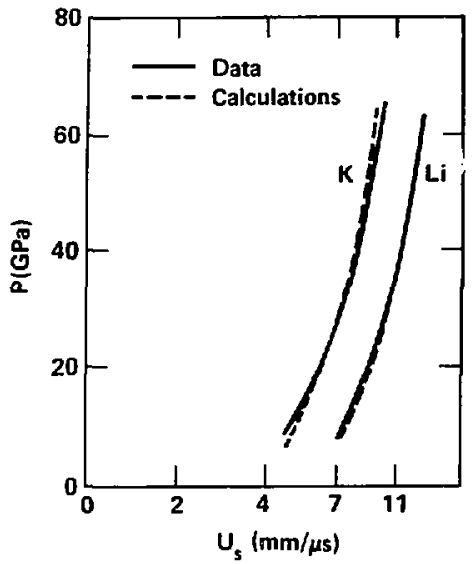

Figure 7. Comparison of Hugoniots calculated with Eq. (2) using the correction for relative electron density with data for lithium and potassium.

Table 5. Comparison of the data, the calculated $U_{s}$ values, and the corrected values for the elements with large atomic volumes.

\begin{tabular}{|c|c|c|c|c|c|c|c|c|c|}
\hline \multirow[b]{3}{*}{ ¿lement } & \multicolumn{9}{|c|}{$P$ (GPa) } \\
\hline & \multicolumn{3}{|c|}{20} & \multicolumn{3}{|c|}{40} & \multicolumn{3}{|c|}{60} \\
\hline & $\overline{\text { Data' }}$ & Calc. & Corr: & $\overline{\text { Data }}$ & Calc. & Cort. & $\overline{\text { Data }}$ & Calc. & Cort. \\
\hline Lithium & 9.00 & 10.5 & 9.05 & 11.7 & 12.3 & 11.2 & 13.5 & 14.0 & 13.5 \\
\hline Sodium & 6.50 & 7.70 & 6.64 & 8.60 & 9.00 & 8.20 & 10.3 & 10.3 & 9.90 \\
\hline Potassium & 6.26 & 7.20 & 6.21 & 8.23 & 8.41 & 7.65 & 9.83 & 9.62 & 9.25 \\
\hline Lead & 2.93 & 3.40 & 2.93 & 3.54 & 3.98 & 3.62 & 3.78 & 4.55 & 4.40 \\
\hline Bismuth & 2.76 & 3.42 & 2.95 & 3.60 & 4.00 & 3.64 & 4.25 & 4.58 & 4.40 \\
\hline
\end{tabular}

- All $U_{s}$ values are given as $\mathrm{mm} / \mu \mathrm{s}$. 


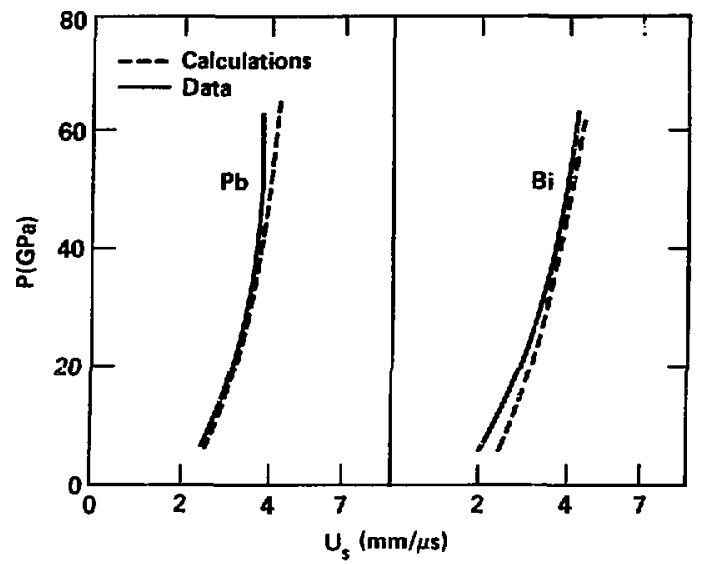

Figure 8. Comparison of Hugoniots calculated with Eq. (2) using the correction for relative electron density with data for lead and bismuth.

An alternative method that can improve still further the data fit for the elements with relatively small average electron derısities, particularly at lower pressures $(<40 \mathrm{GPa})$, is to select one element in a group as the $f(P)$ model for that group.

Equation (6) is derived from averaged values of these low electron dencity elements. Table 6 shows representative shock velocity values for lithium, sodium, potassium, lead, and bismuth based on this equation:

$f(P)=\left(3.7 P+12.1 P^{1 / 2}+6\right)$.

The valtees for lithium, sodium, and bismuth are plotted in Fig. 9.

It appears that at the lower shock pressures $(<50 \mathrm{GPa})$ the interatomic potentials on these larger atoms induce the atoms to move more rapidly under shock loading without deforming too much and without absorbing too much energy. However, at the higher pressures these relatively weak interatomic repulsive forces are rapidly overcome, and the higher repulsive forces of the inner core electrons become dominant, so that the electron density correction is unnecessary.

All of these second-order effects resulting from electronic structure appear to become less important with increasing pressure, and when $P>60 \mathrm{GPa}$ the shock velocity curves become more nearly parallel and in some cases even tend to cualesce.

Our molecular dynamics calculations indicate that many chemical bonds would be broken by shock waves of high intensity. The experimental

Table 6. Comparison of the data and the calculated values of $U_{s}$ using Eq. (6) for the elements with large atomic volumes.

\begin{tabular}{|c|c|c|c|c|c|c|c|c|c|c|}
\hline \multirow[b]{3}{*}{ Element } & \multicolumn{10}{|c|}{$P(\mathbf{G P a})$} \\
\hline & \multicolumn{2}{|c|}{10} & \multicolumn{2}{|c|}{20} & \multicolumn{2}{|c|}{40} & \multicolumn{2}{|c|}{60} & \multicolumn{2}{|c|}{100} \\
\hline & $\overline{\text { Data }^{2}}$ & Calc. & $\overline{\text { Data }}$ & Calc. & $\overline{\text { Data }}$ & Calc. & $\overline{\text { Data }}$ & $\overline{\text { Calc. }}$ & $\overline{\text { Data }}$ & Calc. \\
\hline Lithium & 7.40 & 7,47 & 9.00 & 8.89 & 11.7 & 11.1 & 13.5 & 129 & 15.5 & 16.0 \\
\hline Sudium & 4.95 & 5.49 & 6.50 & 6.5 & 8.60 & $8.14^{\prime}$ & 10.3 & 9.46 & 127 & 11.7 \\
\hline Potassium & 4.70 & 5.13 & 6.26 & 6.10 & 8.23 & 7.60 & 9.83 & 8.84 & 12.5 & 11.0 \\
\hline Lead & 2.50 & 2.43 & 2.93 & 2.89 & 3.54 & 3.60 & 3.78 & 4.18 & 4.80 & 5.18 \\
\hline Bismuth & 2.20 & 2.44 & 2.76 & 2.90 & 3.60 & 3.62 & 4.25 & 4.21 & - & 5.21 \\
\hline
\end{tabular}

All $U_{s}$ values are given as $\mathrm{mm} / \mu \mathrm{s}$. 


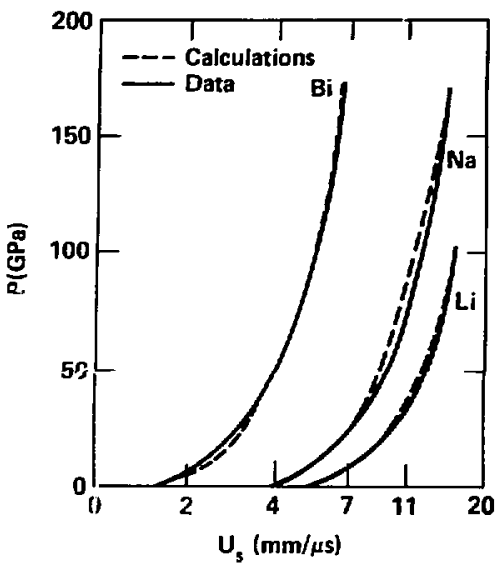

Figure 9. Comparison of Hugoniots calculated with Eq. (2) and the $f(P)$ given as Eq. (6).

work of Graham ${ }^{12}$ with shocked plastics, Dremin and Breusov ${ }^{13}$ with many organics, the experimental ${ }^{14}$ and theoretical studies ${ }^{15}$ of Dodson et al., and the spectroscopic investigation of shockinduced reactivity in nitromethane by Granholm and Duvall ${ }^{16}$ and in benzene by Holmes et al. ${ }^{17}$ add validity to this view of significant chemical bond fracture in highly shocked materials. This could be a factor in the similarity and order in the Hugoniots of the elements at very high shock pressures, because the electronic bonding forces would become less significant.

\section{Correlation with Sonic Velocities}

An assemblage of Hugoniot curves where $U_{s}$ is given as a $f(P)$ (see Fig. 10) shows that the curves cross each other, cross the $P=0$ axis at different points (as they should, because the $P=0$ value should denote the approximate sonic velocity), and yei they all begin to rise quite sharply near $40 \mathrm{GPa}$. As discussed above, the MD calculations gave good values for the sonic velocities of the organic-iike lattices, and with general Eqs. (2) and (3), the sonic velocities were approximated for most of the 22 elements considered. However, the sonic velocities for the Group IA

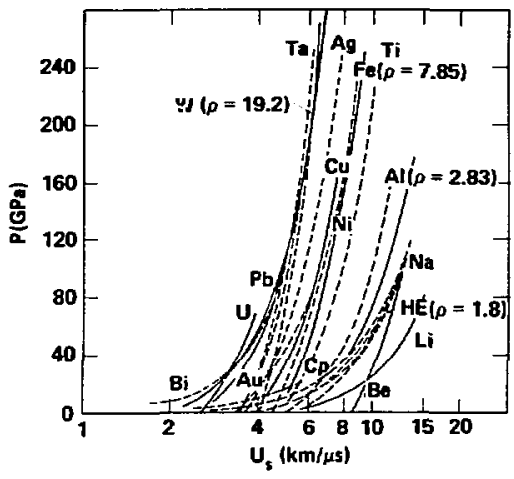

Figure 10. Hugoniol curves prepared from data given in Ref 9.

elements calculated with Eq. (6) are much closer to the data. ${ }^{10}$

The data curves for liquid $\mathrm{N}_{2}$ and $\mathrm{O}_{2}$ show shock velocities substantially lower at the lower shork pressures $(<20 \mathrm{GPa})$ than those calculated by Eq. (2), and the measured sonic velocities are very low- $1.5 \mathrm{~mm} / \mu \mathrm{s}$ for $\mathrm{N}_{2}$ and 2.0 for $\mathrm{O}_{2}$. Because the initial vibrational velocities of the $\mathbf{N}_{2}$ and $\mathrm{O}_{2}$ atoms at $75 \mathrm{~K}$ and $77 \mathrm{~K}$, respectively, where the sonic velocities were measured, would have been much slower than at standard temperature, this should provide a partial explanation for this deviation.

Table 3 compares the calculated sonic velocities [obtained from Eq. (2) with the appropriate $f(P)$ equation by setting $P=0$ ] and measured (as extrapolated from the $I_{s}$ data ${ }^{10}$ sonic velocities of the $\mathbf{2 2}$ elements included in this study. The correlation is a good indication of this fundamental relationship between $r_{A}, \omega_{A}, \rho$, and $U_{s}$, because $P$ is not a factor here.

\section{Shock Velocity Variations with Density}

It has been observed in Teflon ${ }^{10}$ that an increase in density gives a lower $U_{s}$ at constant $T$ for a given $P$ (see Fig. 11). Using Eq. (2) to calculate the effect of density changes in Teflon, the results fit quite well with the data, as shown in Table 7 and Fig. 11. 


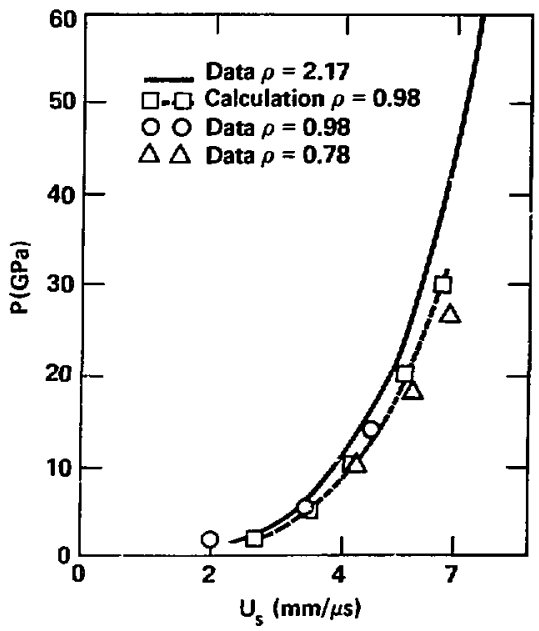

Figure 11. Teflon Hugoniots at densities of $0.78,0.98$, and $2.17 \mathrm{~g} / \mathrm{cm}^{3}$ compared with the calculation of density change from 2.17 to 0.98 using Eq. (2).

The equations thus show the opposing effects of density change from porosity and from heavier particles due to larger $\omega_{A}$, as seen in experiment.

\section{Shock Velocities in Compounds and Mixtures}

It is possible that Hugoniot plots for compounds and some mixtures may be calculable

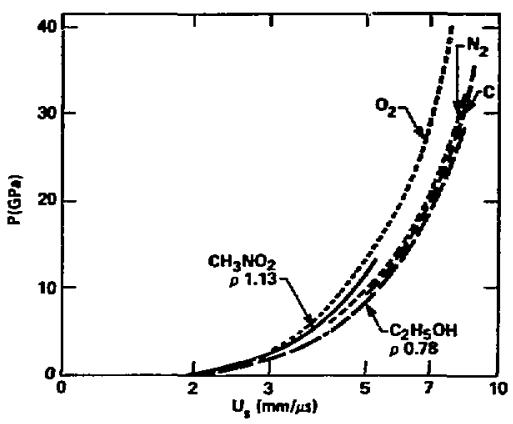

Figure 12. $\boldsymbol{U}_{s}$ vs $\boldsymbol{P}$ curves for nitromethane and ethanol compared with Hugoniots for $\mathbf{C}, \mathbf{N}_{2}$ and $\mathrm{O}_{2}$.

when averaged atomic radii, atomic weights, and densities are considered. Obviously, the structure and extent of voids and the effects of other complicating factors such as the extent of heterogeneity, new crystalline forms, coordination bonding, et.., must be aralyzed. Hcwever, as illustrated in Fig. 12, the Hugoniots for both nitromethane and ethand fall near the curves for $\mathrm{C}, \mathrm{N}_{2}$, and $\mathrm{O}_{2}$ (see Table 8). Ethanol, with the lower density and higher atomic fraction of $\mathbf{H}$, has the higher shock velocity for a given $P$, as we would anticipate froin this analysis. There is some evidence that explosives with higher atomic fractions of hydrogen have higher than expected (from a thermodynamic perspective) detonation velocities, i.e., some mádo from mixtures containing hydrazines and hydrazine compounds.

Table 7. Comparison of shock data and calculated values for the shock velocities in Teflon of different densities.

\begin{tabular}{ccccc}
\hline \multirow{2}{*}{$\begin{array}{c}\text { Shock } \\
\text { velocity }\end{array}$} & \multicolumn{3}{c}{ Density $\left.\left[\mathrm{igcm}^{3}\right)\right]$} \\
\cline { 2 - 5 } & 2.17 & 0.98 & 0.78 & $\frac{\text { Calculated }^{\mathbf{b}}}{0.98}$ \\
\hline 2 & 2.40 & 2.20 & 2.80 & 2.60 \\
6 & 3.20 & 3.32 & 3.72 & 3.47 \\
10 & 3.80 & 4.10 & 4.42 & 4.22 \\
20 & 5.00 & 5.50 & 6.90 & 5.45 \\
30 & 5.85 & - & 7.20 & 6.33 \\
40 & 5.60 & - & - & 7.15 \\
\hline
\end{tabular}

All $u$, values .ue given in $\mathrm{mm} / \mu \mathrm{s}$.

b The calculater values are derived by making a density cortection to the data at a density of $2.17 \mathrm{~g} / \mathrm{cm}^{3}$ with the use of Eq. (2). 
Table 8. Comparison of data and alculated shock velocity values for liquid $\mathbf{N}_{2}$ and $\mathbf{O}_{2}$.

\begin{tabular}{|c|c|c|c|c|c|c|c|c|}
\hline \multirow[b]{3}{*}{ Element } & \multicolumn{8}{|c|}{$P$ (GPa) } \\
\hline & \multicolumn{2}{|c|}{$10^{x}$} & \multicolumn{2}{|c|}{$20^{\circ}$} & \multicolumn{2}{|c|}{40} & \multicolumn{2}{|c|}{60} \\
\hline & Dats $^{\circ}$ & Calc. $^{\circ}$ & $\overline{\text { Data }}$ & Calc. & $\overline{\text { Data }}$ & Calc. & $\overline{\text { Data }}$ & Calc. \\
\hline $\mathbf{N}_{2}$ & 5.20 & 5.66 & 6.80 & 6.36 & 9.05 & 8.65 & 10.0 & 9.89 \\
\hline$o_{2}$ & 4.42 & 5.27 & 5.78 & 5.92 & 7.72 & 8.04 & 9.16 & 9.20 \\
\hline
\end{tabular}

${ }^{2}$ The $U$, values $\leq 20 \mathrm{GPa}$ are corrected for the low relativa electron density.

bAll $U$, values are given in $\mathrm{mm} / \mu \mathrm{s}$.

Table 9. Summary of equations.

\begin{tabular}{|c|c|c|}
\hline Equation No. & Equation & Use \\
\hline 2 & $u_{s}=f(P)\left(r_{A} / \omega_{A}\right)^{t / s_{p}}$ & Basic equation \\
\hline 3 & $f(P)=\left(0.42 P+10.3 p^{1 / 2}+12\right)$ & $\begin{array}{l}\text { General } f(P) \\
\text { for all elements } \\
\text { shown }\end{array}$ \\
\hline 4 & $f(P)=\left(12.4 P-0.37 P^{1 / 2}+12\right)$ & $\begin{array}{l}\text { Better fil far } \\
\text { few elements } \\
\text { at low } P\end{array}$ \\
\hline 6 & $f(P)=\left(3.7 P+12.1 P^{\prime / 2}, 6\right)$ & $\begin{array}{l}\text { Better fit to } \\
\text { sound velocity } \\
r \text { for elements } \\
\text { with larger } r_{A}\end{array}$ \\
\hline
\end{tabular}

\section{Comments}

Many miechiods of Hugoniot calculations based on electron band theory ${ }^{18,19}$ and different empirical or semiempirical analyses have been developed. However, the simplicity and apparent wide applicability of the method presented here have some appeal.

With Eq. (2) and the small corrections for $f(P)$ and relative electron densities given in Eqs. (4)-(6) (see Table 9), the $U_{s}$ calculations for 22 elements covering the range from lithium to platinum in density, from nickel to potassium in atomic radius, and from 6 rows and 12 element groups in the periodic table can be well correlated to the data. The majority of the values up to $900 \mathrm{GPa}$ are less than $8 \%$ different from the data, and most are within the experimental error.

\section{Conclusions}

We conclude that the method and equations given can be used to calculate to a substantial accuracy the $U_{s}$ vs $P$ (Hugoniot) values for all of the condensed elements, including the liquefied gases. Some of the electronic and structural fea- tures of the elements appear to have decreasing contributions to the shock velocity values as the shock pressures reach higher levels, particularly above $60 \mathrm{GPa}$.

\section{Acknowledgments}

We wish to acknowledge the MD calculations and very helpful discussions of A. M. Karo and J. R. Hardy and significant assistance obtained in discussions with $M$. van Thiel. 


\section{References}

1. M. H. Rice, R. G. McQueen, and J. M. Walsh, Solid State Physics 6, 1 (1958).

2. G. E. Duvall and G. R. Fowles, "Shock Waves," in Fïgh-Pressure Physics and Chemistry. R. S. Bradley, Ed. (Academic Press, London and New York, 1963), Vol. 2.

3. A. M. Karo, J. R. Hardy, and F. E. Walker, "Theoretical Studies of Shock-Initiated Detonations," Acta Astronautica 5, 1041 (1978).

4. F. E. Walker, A. M. Karo, and J. R. Hardy, "Comparison of Molecular Dynamics Calculations with Observed Initiation Phenomena," Proc. 7th Intem. Symp. on Detonation (Annapolis, MD. June 16-19. 1981).

5. A. M. Karo, F. E. Walker, W. G. Cunningham, and J. R. Hardy, "Theoretical Studies of Shock Dynamics in Two-Dimensional Struc:ures. V. Microscopic Constraints on Shock-Induced Signals," Proc. APS 1981 Topical Conference on Sltock Waves in Condensed Matter (Menlo Park, CA, June 23-25, 1981).

6. F. E. Walker, A. M. Karo, and J. R. Hardy, "Non-Equilibrium Effects Seen in Molecular Dynamics Calculations of Shock Waves in Solids," Proc. NATO Advanced Study Institute [El Escorial (Madrid], Spain, August 1-11, 1983].

7. A. N. Dremin and V. Yu Klimenko, "The Effect of the Shock-Wave Front on the Origin of Reaction," Progress in Astronautics and Aeronautics (American Institute of Aeronautics and Astronautics, New York, 1981).

8. A. M. Karo, F. E. Walker, T. M. Deboni, and J. R. Hardy, "The Simulation of Shock-Induced Energy Flux in Molecular Solids," Proc. 9th Intern. Colloq. on Dynamics of Explosions and Reactive Systems (Poitiers, France, July 4-9, 1983).

9. Periodic Table of Elements, Sargent-Welch Scientific Co.

10. M. van Thiel, Gen. Ecl., Compendium of Shock Wave Data, Lawrence Livermore National Laboratory, Livermore, CA, UCRI..50108, Vo1... I-III (June 1977).

11. F. E. Walker, "Description of a Shock Wave Velocity Barrier," Propellants and Explosives 6, 15 (1981).

12. R. A. Graham, "Shock-Induced Electrical Activity in Polymeric Soiids. A Mechanically-Induced Bond Scission Model," J. Phys. Chem. 83, 3048 (1979).

13. A. N. Dremin and O. N. Breusov, "The Chemistry of Shock Compression," Priroda 12, 10 (1971).

14. B. W. Dodson et al., "Subthreshold Generation of Free Radicals in Shock-Loaded Organic Solids," Pres. 4th Ann. APS Topical Conference on Shock Waves in Condensed Malter (Spokane, WA, July 22-25, 1985).

15. P. A. Taylor and B. W. Docison, Simulation of Lattice Damage Due to Dynamic Loading," ibid.

16. R. H. Granholm and G. E. Duvall, "Shock-Induced Reactivity in Nitromethane by Time-Resolved UV-Vis Spectroscopy," ibid.

17. N. C. Holmes et al., "Molecular Emission from Shock-Decomposed Benzene," ibid.

18. S. K. Sikka, "Shock Hugoniot Equation of State-Electron Band Theory Approach," ibid.

19. R. Grover, "An Interpretation of High Pressure Carbon Hugoniot Data Based on Band Theory Calculations," ibid. 